\title{
Effect of handedness on handgrip strength among left-handed normal girls
}

\author{
Abstract \\ Assessment and recording of hand grip strength plays an essential part in the \\ rehabilitation process.
}

Objective: The aim of the study was to investigate how hand dominance could affect the handgrip strength in left handed normal girls.

Subjects: Seventy six female students were selected from King Abdulaziz University in Jeddah with no previous history of diseases or injuries in both upper limbs.

Methods: Using a dynamometer, the strength of Hand grip was assessed in both hands. This procedure was repeated for several trials and recorded the average value.

Results: A significant difference between right-handed and left-handed subjects was detected regarding grip strength ratio of the dominant and the non dominant hands $(\mathrm{P}<0.05)$.

Conclusion: the left-handed young females have weaker handgrip strength than the right-handed ones under normal conditions.

Keywords: hand dominance, grip strength, dynamometer, left-handed people
Volume 2 Issue 4 - 2017

\author{
Enas Elsayed,' Rasha hegazy, ${ }^{1,2}$ Heba \\ Mohammed, ${ }^{2,3}$ Mohamed Fawzy, ${ }^{2,4}$ Emad \\ Salam, ${ }^{2}$ Rawan Alzahrani, ${ }^{2}$ Asrar Almouallad, ${ }^{2}$ \\ Shaima'a Barasheed ${ }^{2}$ \\ 'Department of Physical Therapy for Neuromuscular Disorders \\ and its Surgery, Cairo University, Egypt \\ 2Department of Physical Therapy, King Abdulaziz University, \\ Saudi Arabia \\ ${ }^{3}$ Department of Physical Therapy for Obstetrics and \\ Gynecology, Cairo University, Egypt \\ ${ }^{4}$ Department of Growth and Development in Children and its \\ Surgery, Cairo University, Egypt
}

\begin{abstract}
Correspondence: Enas Elsayed, Department of Physical Therapy for Neuromuscular Disorders and its Surgery, Faculty of Physical Therapy, Cairo University, Egypt, Email drinaselsayed@yahoo.com
\end{abstract}

Received: December 18, 2017| Published: December 28, 2017

\section{Introduction}

Numerous every day activities and functions require high action of hands. Hand grip strength is a physiological variable that is affected by some factors such as age, gender, body size and others. The estimation of hand grip strength is of immense importance in determining the efficacy of different treatment strategies of hand and also in hand rehabilitation. ${ }^{1,2}$ Grip strength provides a valuable and objective index for upper extremity functions. It is a potential tool for clinical assessment as it provides a well established and objective score that is reflective of hand function which is easily and quickly obtainable by different health professionals. ${ }^{3}$ The handgrip strength is measured by quantifying the isometric force of the hand musculature around the handle of a dynamometer. ${ }^{4}$ Using handgrip dynamometry to assess grip strength is considered a basic standard parameter for the assessment of the functionality of the hand. ${ }^{5}$ The handgrip strength testing is a valid and reliable easy measure of muscle strength which uncover more than the quality of individual's handgrip. ${ }^{6}$ It helps to establish a database of normal population with reference values. ${ }^{7}$ The handgrip strength test is important for selecting the treatment protocol, set realistic goals along the process of rehabilitation, and to predict the overall strength and endurance of the patient. ${ }^{8}$ There is a direct connection between hand hold quality, body, wrist and forearm position as hand and forearm muscles are vital in the grasp quality. ${ }^{9}$ While some researchers reported that hand dominance had no important influence on grip strength, ${ }^{10-12}$ others identified significant differences. ${ }^{13}$

\section{Aim of the study}

The aim of the current study was to evaluate the grip strength of both hands for the right and left-handed females to detect if there is effect of hand dominance on hand grip strength. The results could be used as a reference normal values which is important for follow up of the rehabilitation outcomes when dealing with left-handed people.

\section{Materials and methods}

\section{Subjects}

Seventy six female subjects (60 right-handed, 16 left-handed) were selected from King Abdulaziz University, with age ranged from $14-25$ years (mean $\pm \mathrm{SD}=21.08 \pm 1.77$ ), and with no previous injuries in both upper limbs. Exclusion criteria were previous injuries, fracture or deformity in upper limbs. Subjects were assigned into two groups, right handed and left handed.

\section{Methods}

Hand grip dynamometer in this study was Jamar (hydraulic hand dynamometer). Model 12-0103, Made in USA. As it has a high reliability it is the most widely used instrument. ${ }^{14}$ A consent form was obtained from each subject prior the beginning of the study. Assessment procedure: All subjects assumed sitting position on a chair with back support with 90 degrees elbow flexion and fixed close to the body, back is straight and supported on the chair back, hips are at right angle with the knees and the knees at right angle with the ankles.

All subjects were directed to press on the handle and hold for a few seconds, then relax for 30 seconds to help maximum recovery of the muscles of the hand and forearm. This procedure was repeated three trials for each hand starting with the dominant hand. The average value among the three trials was recorded. 


\section{Data analysis}

Means and standard deviation (SD) were calculated for all quantitative data using SPSS program, version 16 and were presented as figures using Microsoft Excel 2007. Unpaired t-tests were used to compare data with $\mathrm{P}$ value less than 0.05 .

\section{Results and discussion}

\section{Hand grip strength}

The results of Hand grip strength showed that there was a difference between dominant and non-dominant hands in both right and left-handed participants (Table 1) (Figure 1). In right-handed participants, there was a statistically significant difference between the grip strength of dominant and non-dominant hands in favor of the dominant hand $(\mathrm{p}=0.004)$. On the other hand, in the left-handed group, there was no significant difference between dominant and nondominant grip strength $(\mathrm{p}>0.05)$.

Table 1 Mean values of hand grip strength of the dominant and non-dominant hands in both groups

\begin{tabular}{lll}
\hline Hand grip strength (Kgm) & Right handed & Left handed \\
\cline { 2 - 3 } & Mean \pm SD & Mean \pm SD \\
\hline Dominant hand & $18.15 \pm 6.35$ & $19.59 \pm 5.98$ \\
Non-dominant hand & $16.74 \pm 7.14$ & $19.22 \pm 4.90$ \\
P & $0.004^{*}$ & 0.58 \\
\hline
\end{tabular}

*Significant

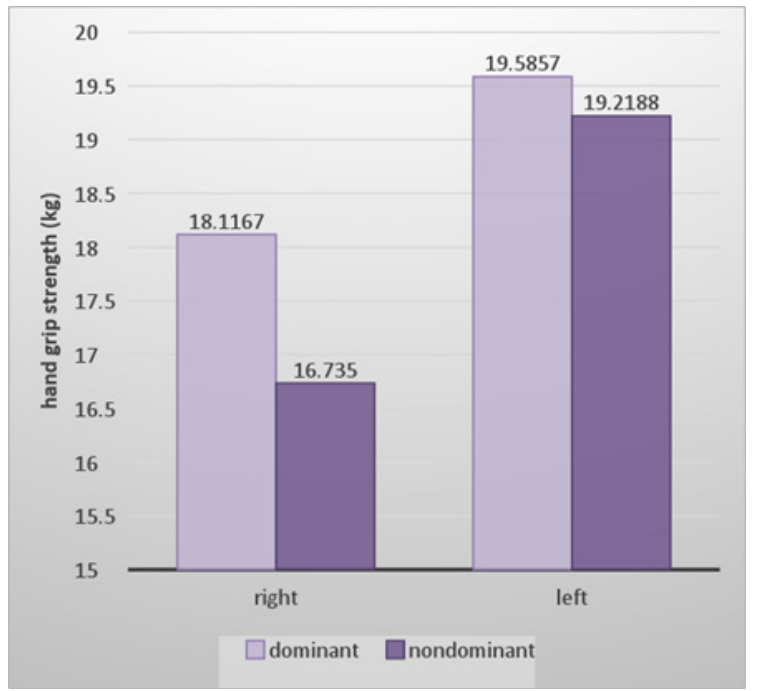

Figure 1 Mean values of handgrip strength in both dominant and non-dominant right and left handed participants.

\section{Grip strength ratio}

The study approved a significant increase in the hand grip strength ratio in right-handed subjects compared to that of the left-handed ones $(p<0.05)$ (Table 1) \& (Figure 1). The effectiveness of specific physical treatment could be evaluated through progress in hand strength when compared with norms. The current study aimed to determine the effect of handedness in normal left-handed young females on their handgrip strength when compared to right-handed ones. The findings indicated that in the right-handed participants, the dominant hand has about $9 \%$ grip strength greater than that of the non-dominant one. This was agreed with the results of Petersen et al..$^{15}$ and Arora ${ }^{16}$ who tested the $10 \%$ rule utilization in the rehabilitation of hand dysfunctions. The $10 \%$ rule stated that "there is a greater $10 \%$ hand grip strength in dominant hand more than the non-dominant one". This rule can helps physical therapists in determining treatment objectives for handinjured subjects. They concluded that the $10 \%$ rule is valid only for right-handed persons but for left-handed persons, the grip strength in both hands should be considered equivalent

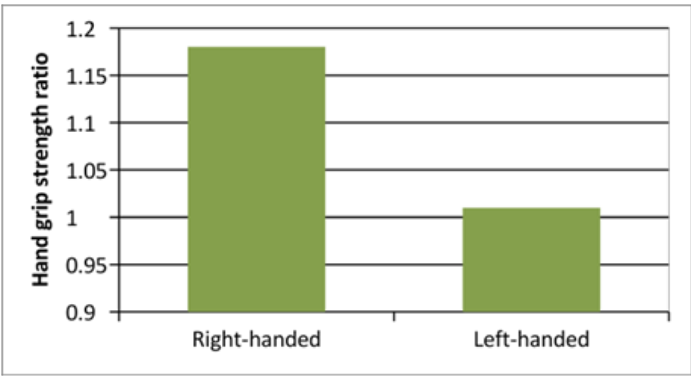

Figure 2 Mean values of grip strength ratio in the right and left handed participants.

Table 2 Comparison between mean values of grip strength ratio (dominant/ non-dominant) in the right and left handed participants

\begin{tabular}{lll}
\hline & Right handed & Left handed \\
\hline & Mean \pm SD & Mean \pm SD \\
\hline Ratio & $1.18 \pm 0.47$ & $1.01 \pm 0.13$ \\
P & $0.015^{*}$ & \\
\hline
\end{tabular}

*Significant

Additionally, the results showed significant increase of the hand grip strength of dominant compared to the non-dominant hands in right-handed participants which was not the case for left-handed females. This is supported by Incel et al. ${ }^{17}$ who concluded that the dominant hand was significantly stronger in the right- handed subjects but no such significant difference between sides could be documented for left-handed people. On the other hand, Koley et al. ${ }^{18}$ reported that when comparisons were made between dominant right and left hand groups and non-dominant right and left hand groups, both in males and females, no statistically significant differences were noted in any case.

Moreover, the findings of the present work are similar to that of Ziyagil et al. ${ }^{19}$ who found no significant difference between right and left hand grip strength in athletics and found that the grip strength of the non-dominant hand was less than that of the dominant one in both right and left handed groups. In contrast, Crosby et al. ${ }^{20}$ reported that a remarkable number of both left and right-handed participants had a stronger non dominant hand. About $29 \%$ of the left handed participants and $20 \%$ of the right-handed participants had a range of differences in the grip strength between $15 \%$ and $30 \%$ for their two hands.

The grip strength ratio is a valuable tool in the assessment of patients who had problems in the non-dominant hands and easy to be revised for the follow up process. The results of the grip strength ratio in the current work were correlated with those obtained by Beumer 
et al. ${ }^{21}$ They indicated that grip strength ratio showed a significant difference between right and left-handed females regarding normal hand grip strength. This necessitates referring to normal ranges of grip strength specific for left-handed people for rehabilitation purposes. On the contrary, Balogun et al..$^{22}$ compared the strength of selected muscle groups in right and left limb dominant subjects and calculated the hand grip strength ratio for each participant. They concluded that both right and left limbs had a similar ratio.

\section{Conclusion}

It could be concluded that left-handed normal young women tend to have less hand grip strength than right-handed ones.

\section{Acknowledgements}

Great thanks for all the participants of the study.

\section{Conflict of interest}

The author declares no conflict of interest.

\section{References}

1. Malina R, Zavaleta A, Little B. Body size, fatness and leanness of Mexican American children in Brownsville, Texas: Changes between 1972 and 1983. Am J Public Health. 1987;77(5):573-577.

2. Ross C, Rösblad B. Norms for grip strength in children aged 4-16 years Acta Paediatrica. 2002;91(6):617-625.

3. Cheung C, Nguyen D, Eleanor A, et al. Association of handgrip strength with chronic diseases and multimorbidity-A cross-sectional study. Age. 2013;35:929-941.

4. Trampisch US, Franke J, Jedamzik N, et al. Optimal Jamar dynamometer handle position to assess maximal isometric hand grip strength in epidemiological studies. J Hand Surg Am. 2012;37(11):2368-2373.

5. Fernandes A, Brito J, Vieira C, et al. Effect of peripheral muscle fatigue during the testing of handgrip strength. Fisioter Mov. 2014;27(3):407-412.

6. Clarke, A, Clerke J. A literature review of the effect of handedness on isometric grip strength differences of the left and right hands. American Journal of Occupational Therapy. 2001;55(2):206-211.

7. Werle S, Goldhahn J, Drerup S, et al. Age and gender-specific normative data of grip and pinch strength in a healthy adult Swiss population. J Hand Surg Eur. 2009;34(1):76-84.
8. Westropp MN, Gill T, Taylor A, et al. Hand Grip Strength: age and gender stratifi ed normative data in a population-based study. BMC Res Notes. 2011;4:127.

9. Manohran V, Sundaram S, Jason J. Factors affecting hand grip strength and its evaluation. Int J Physiother Res. 2015;3(6):1288-1293.

10. Ager C, Olivett B, Johnson CL. Grasp and pinch strength in children 5 to 12 years old. Am J Occup Ther. 1984;38(2):107-113.

11. Mathiowetz V, Wiemer D, Federman S. Grip and pinch strength: norms for 6- to 19-Year-Olds. Am J Occup Ther. 1986;40(10)705-711.

12. Butterfield S, Lehnhard R, Loovis E, et al. Grip strength performances by 5- to 19-year olds. Percept Mot Skills. 2009;109(2):362-370.

13. Armstrong C, Oldham J. A Comparison of dominant and non-dominant hand strengths. J Hand Surg Br. 1999;24(4):421-425.

14. Roberts H, Denison H, Martin H, et al. A review of the measurement of grip strength in clinical and epidemiological studies: towards a standardized approach. Age and Ageing. 2011;40(4):423-429.

15. Petersen P, Petrick M, Connor H, et al. Grip strength and hand dominance: challenging the 10\% Rule. Am J Occup Ther. 1989;43(7):444- 447.

16. Arora S. Application of $10 \%$ rule in pinch strength, hand dominance on Indian population. Indian Journal of Occupational Therapy. 2013;45(1):10-14.

17. Incel N, Ceceli E, Durukan P, et al. Grip strength: effect of hand dominance. Singapore Med J. 2002;43(5):234-237.

18. Koley S, Singh PA. Effect of hand dominance in grip strength in collegiate population of Amritsar, Punjab, India. Anthropologist. 2010;12(1):13-16.

19. Ziyagil M, Gürsoy R, Dane Ş, et al. Effects of handedness on the hand grip strength asymmetry in Turkish athletes. Comprehensive Psychology. 2015;4(20):1-6.

20. Crosby CA, Wehbé MA, Mawr B. Hand strength: normative values. $J$ Hand Surg Am. 1994;19(4):665-670.

21. Beumer A, Lindau T. Grip strength ratio: A grip strength measurement that correlates well with DASH score in different hand/wrist conditions. $B M C$ Musculoskelet Disord. 2014;15:336.

22. Balogun J, Onigbinde A. Hand and leg dominance: Do they really affect limb muscle strength? Physiotherapy Theory and Practice. 1992;8(2):8996. 